
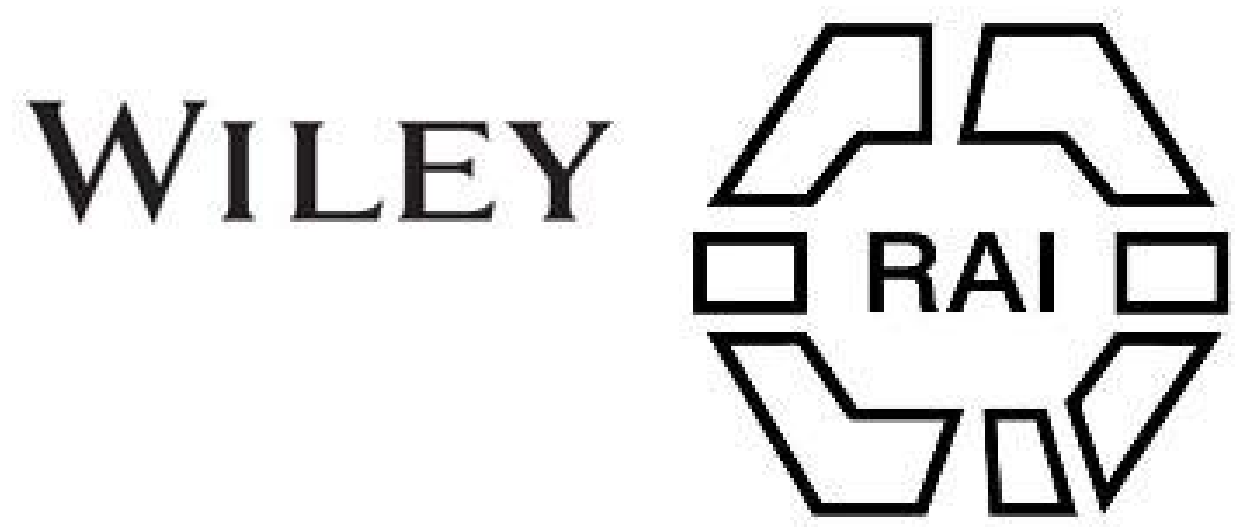

\title{
11. History and Ethnology in Central Asia.
}

Author(s): M. A. Czaplicka

Source: Man, Vol. 21 (Feb., 1921), pp. 19-24

Published by: Royal Anthropological Institute of Great Britain and Ireland

Stable URL: http://www.jstor.org/stable/2840729

Accessed: 26-06-2016 01:41 UTC

Your use of the JSTOR archive indicates your acceptance of the Terms \& Conditions of Use, available at

http://about.jstor.org/terms

JSTOR is a not-for-profit service that helps scholars, researchers, and students discover, use, and build upon a wide range of content in a trusted digital archive. We use information technology and tools to increase productivity and facilitate new forms of scholarship. For more information about JSTOR, please contact support@jstor.org.

Wiley, Royal Anthropological Institute of Great Britain and Ireland are collaborating with JSTOR to digitize, preserve and extend access to Man 
that the headles are not pulled askew. This adjustment is affected by the femoral of hares, the position of which, just below the pulleys, is seen in the illustration (Plate B). Why hare bones are used I never could discover, but the preference for them seemed to be almost universal even though, apparently, little bits of wood or metal would have served equally well or better. To weave with four headles a double harness is used, each pair of headles having its own two pulleys and these two pulleys being connected with the two main pulleys, thus using six pulleys in all.

The alternate raising and depressing of the headles is done by treadles, which consist of flat pieces of wood, through the short axis of which a pin runs forming a simple crank; between each treadle a small round hollow bit of wood is put in as a bearing. Two bits of string tie the treadle to its appropriate headle. In some cases a single bit of string is used, as the distribution of the pull of the treadle is assured by fixing a kind of spare headle shaft some inches below the headles. When four headles are in use, the usual arrangement of the treadles is 2431 , though some weavers prefer to use the left-hand treadle first. Beyond the headles is the cross, the lease rods being usually any odd bit of stick. There is often a supplementary cross, usually a forked stick, carrying the bundles of the warp as taken off the warping board. Next to the cross a weight is hung. This weight is an object on which the weaver, especially if she be young, lavishes a lot of attention, a favourite ornament is a loom weight out of an old tomb; sometimes a highlycoloured bit of cloth is used. One girl shewed me with great delight a bell which tinkled as she wove. Beyond the weight the warp passes over a bar and is then carried under another bar up to the ceiling and then is attached to a peg behind. the weaver or in some cases it is kept taut by a heavy weight.

The temple, or instrument for keeping the cloth of the right width, is made of two flat pieces of wood about $2 \mathrm{cms}$. wide, furnished at one end with a metal spatulate end in which teeth are cut; to one of these pieces of wood some string or wire is attached, and to this a metal hook, which is fastened into a hole in the other piece, the whole can be adjusted to the right width and the little teeth grip the selvedge. The shuttle is about $20 \mathrm{cms}$. long; it is made of hard wood pointed with iron.

In order to weave with a double warp the following additions are made to the loom :-The warps are weighted separately, and then carried over two separated bars one on top of the other at the end of the loom above the weaver's head; they are then carried to the distal end of the loom and similarly over two bars, an extra bar, often merely an odd bit of stick, being inserted $20 \mathrm{cms}$. or so above the bar, which normally raises the warp distal to the lease rods; slightly proximal to this latter bar the separate warps are united together through the lease rods as a single warp. In all the cases that $I$ saw of this form of weaving the warps were weighted. It is not impossible, however, that sometimes they are tied to a peg behind the weaver's back.

L. H. DUDLEY BUXTON.

Central Asia.

Czaplicka.

History and Ethnology in Central Asia. By M. A. Czaplicka.

There are two objects in this paper. One is theoretical, relating to the II connection existing between history and ethnology, a relation very much open to improvement; the other is to show one of the practical issues, or shall I say one of the practical mistakes, which occurred in my special region, North-Central Asia, owing to this misunderstanding between ethnology and history. The particular mistake to which I am referring is the wrong use of the terms Mongol and Tartar, the kind of terms on the meaning of which the ethnologists, when pressed for an 
accurate definition, look round for an avenue of escape, while historians will bluntly quote you the date on which Mongols and Tartars are first heard of in history, as if this explains who they are. I shall venture to deal with these two names later. Now allow me to make a strong attack on the position which ethnology occupies towards history and history towards ethnology.

We learn in modern history things which could not possibly stand a critical or ethnological searchlight; for instance, we hear of one nation having as its distinguishing characteristics blue eyes and fair hair, while from ethnology we learn that within one nation, say the French, we have in the northern districts blue eyes and fair hair, and in the south dark eyes and dark hair; that it is merely a question of geographical environment influencing a physical type over a long period. Or else you hear of a race being by nature warlike, while it is enough to study a little the human mind, say during the last war, to know that the most unwarlike people, like the British, can become warlike under some circumstances. In a word, the modern teaching of history has suffered from an inadequate treatment of its ethnological background: we learn a catalogue of events relating to a branch of mankind without understanding the working of the mind and body of that branch.

I do not wish to create the impression that I am running down the branch of learning, history, because it is not my own, for I only took history first as a matter of courtesy; but my challenge is equally strong in regard to ethnology in cases in which it disregards the background of history. Take an ethnologist who goes to a field, study, and finds among the primitive people, as, for instance, the Indians of North-Western America, the institution of patriarchy and matriarchy existing alongside, sometimes in the same tribe. The only conclusions he can come to is that their logic burns the candle at both ends, or otherwise that the people obviously have a mentality quite opposite to our own; unless, of course, this ethnologist chooses to learn the history of the people and of their migrations and contacts, and finds that one of these institutions, say matriarchy, has arisen under special geographical circumstances at the time when the people who now live on the coast lived in the interior as seasonal hunters. I can quote many absurd instances of the difficulty of dealing with ethnological facts of a given moment without allowing for the perspective of time. But, on the other hand, such a method has been almost entirely abandoned, especially in this country where the evolutionary method of Sir Edward Tylor and the genealogical method of Dr. Rivers bring, in fact, some history to ethnology. To be quite just, it must be said that the area which has been best studied by the historians, the Mediterranean of the classic world, has allowed a little for ethnological fact, but it is only due to the circumstance that Sir William Ridgeway, Professor Gilbert Murray, and Professor John Myres have chosen to learn some anthropology in addition to their vast knowledge of classical history, and not because ethnology was generally recognised by the historians, and those who teach history.

What is the real relation between history and ethnology? If it be granted that history is the recorder of selected events of importance concerning mankind, ethnology and anthropology are concerned with the description of the whole nature and behaviour of man. Now, if you allow that we cannot understand the exceptional state of mind of a man without knowing his normal nature, then you must agree that we cannot understand history with having some ethnological knowledge.

But of course once we make it ethnological history, just as there is legal or economic history, the subject of history will cease to be merely dry chronology.

For North-Central Asia the historians have given us on the one hand a list of wars and invasions; on the other, a description of artistic productions. So far, 
so good. But to each of these peoples who waged wars and to each of them who produced artistic bronzes and jades, a name has been attached by historians, a name which perhaps belonged only to the invading general, and such names have found their way into handbooks of ethnology as racial terms. Thus, such expressions as the Mongol race or Mongol eyelid, or Tartar despotism or Tartar culture, have been popularised, though under a close examination there was never a Tartar or Mongol race, as such, but the name has been placarded on some branches of Turkic or Tungusic races when found under certain circumstances.

When dealing with Central Asia, ethnologists can less dispense with history than in any other case, but they must be most careful in sifting the historical information. Naturally, the mention of the classical historians relating to Asiatic peoples would be vague and misleading. We all know the controversies as to who the Scythians were. The Arabic historians give us more speculative material, but it is the Chinese annals that present the most gratifying materials for ethnological knowledge of Central Asia. Seeing that Eastern Europe is larger than western, and that even Western Europe is affected by races of North-Central Asia, though to a smaller degree than eastern Europe, it ought to be as much our aim to work out ethnology found in the Chinese annals as the working out of the ethnology of ancient Egypt or of Babylon. Under the circumstances it may be expedient to try first of all to throw ethnological light upon the last great racial regrouping which occurred in Asia and Europe in the time of Jinghis Khan, and then only, after examining the most recent facts first, to pass to the racial changes introduced at the time of Attila.

The existing classification of North-Central Asia stretching also to eastern Europe, while professedly ethnological, is based on the history relating to the Jinghis Khan invasion. This classification calls all Asiatic peoples nearest to the Slavs, "Ural-Altaic," for it is supposed that all these peoples either originated in the Altai, or have passed through the Urals and the Altai on their way to Europe. This group is said to comprise five " races," Finnic, Samoyedic, Turkic, Tungusic and Mongolic, races which, according to the Finnish linguist Castren, are said to be linguistically akin. We shall leave on one side the Finnic race, which at least geographically seems to belong more to eastern Europe than to Asia. 'We shall also pass over the Samoyeds, who seem to have been an Arctic race for at least a very considerable time, and there remain the three "races" which are truly North-Central Asiatic, the Turkic, Tungusic and Mongolic. The difficulty before us now is to find out whether there are at the present time and whether there existed in the past three different races called by those names.

Taking first these people, as they are to-day, they are of course very much mixed with each other as well as with the Chinese, Russians and Northern Asiatics, called Palæo-Siberians, etc. But yet, by a careful study of many individuals of each of these three groups, one forms a hypothesis that there is a defined physical type, or types, of a Tungus as well as of a Turk, meaning Turk in Central Asia. More than in physical type, they are well defined in their customs, arts and crafts, in their language and mythology. But now taking the Mongols, they cannot be treated as opposed to either of the other two races. They are in physique and culture either like the Tungus or the Turk; or else they combine the traits of both. What people usually call the Mongol physical type, that is, very large and round head, very broad face with prominent cheekbones, with the eyes slightly tilted upwards, and a Mongolian eyelid, with small flat nose and straight, dark hair, this type is found more often and more complete among the Turks in North-Central Asia than among the so-called Mongols, as the anthropometric statistics of a Russian Professor, Ivanowski, have shown. What is called Mongol culture, i.e., 
the steppe nomad life, cattle breeders and horse-riders with various social institutions accompanying this mode of life, is again found more typically developed among the Tungus than among the "Mongols" of to-day. In fact, if the Mongols differ from the Tungus, it is only because all their institutions are less stable owing to admixture with other elements, chiefly Turkic. The only conclusion that can be made from the present state of affairs is, that either the Mongol people in the past were better defined than they are at present and that the Turks and Tungus were sub-races branching from the Mongols, or that there were two well-defined races, that of Turks and that of the Tungus, and that the Mongols are the bridge between them, formed by those Turks and Tungus who, owing to proximity, invasions and political changes, mixed most one with the other. And here we have just a case in which we cannot deal with present conditions without going back into the past. I now propose to deal with their past as found in Chinese sources, and I propose to keep to one translator whose translations are verbal and fairly free from subjective views, even though meagre as literature. He was an orthodox monk in China almost two centuries ago. His name is Father Iakinth Bichurin.

The name Mongol, as well as the other widely-spread name Tartar, appears first in Europe at the beginning of the thirteenth century and was given to the Asiatic people led by Jinghis Khan. Let us see how far back we can trace these two names in the history of Central Asia as recorded by the Chinese. We know that the Chinese used to make comment and observations on the two powerful neighbours of inferior culture to themselves, the north-western neighbours who in the pre-Christian era were called Hiung-nu and since the sixth century adopted the name Tu-kiu, i.e., Turks, and the north-eastern neighbours called Tung-hu, the present Tungus, of whom Manchu is one branch. From as early as 3000 в.c. China had to wage wars with these two neighbours and occasionally make alliances with them. The Tungus always had closer connections with the Celestial Empire, and were also more affected by the Chinese civilisation, while the Turks had in addition been influenced by the various Iranian civilisations of ancient Turkestan. We have, however, nothing like as long a genealogy for the Mongols. In fact, we hear about the clan of Mongol, of the confederacy of Tatan, only some hundred years before Jinghis Khan. As to the name Tartar, it appears much earlier, in about the eighth century, as a clan name, which a little bit later, in the eleventh century, joined the confederation of clans called Tatan, just as did the clan of Mongol. It must therefore be remembered that the derivation of Tatar from Tatan (Klaproth) is wrong because these two names are not synonymous, the name Tatan, or as it is occasionally spelt, Tata, is a name for the confederation of clans (aiman) of which in the eleventh century the strongest were Mongol Taigut, Kere and Tatar. Jinghis Khan himself belonged to the Mongol clan of the Tatan confederacy and he subdued all the other clans of his confederacy before he started his conquests outside Asia. He adopted the name of the confederacy, Tatan, as the name of his dynasty, and this name lasted until Khubilai Khan, who adopted for his dynasty the name Yuan. Hence the Tatars were only one of the very many clans composing the army of Jinghis Khan. It is just possible that this clan was fairly well represented among the invaders of eastern Russia and that the Russians mistook Tatan and Tatar for one word. Planode Carpini, who was sent as an envoy from the Pope of Rome to the Khan Kuyuk, followed the same mistake, and after him the geographers began to call all North-Central Asia from the Caspian to the Chinese Sea the Great Tartary. On the other hand, in Eastern Russia in the Volga district, this name was given also to the purely Turkish invaders who followed Jinghis Khan, namely, the Tamerlane invasion, and all the Turkic Khanates of Kazan, Astrakhan and Crimea were called Tatar Khanates. Hence 
we see that although the clan of Mongol was very small in comparison to the Jinghis Khan army, comprised of almost one-third of all the Asiatic peoples, and even the Tatan confederacy could not be numerically compared to all the other confederacies' carried to Europe by Jinghis Khan, but the fact that that remarkable man belonged to the Mongol clan and Tatan confederacy has made European people call the Turks and Tungus of his army by the name Mongol or Tatan. That the name of one clan, Tatar, replaced the name of the confederacy Tatan is merely a question of incidental mistake. Besides, in Central Asia, the clan name Tatar is older than the confederacy name Tatan. We hear of the name Tatan at the beginning of the ninth century and of the Otui and Tokus Tatars in about the seventh century.

So far I have concerned myself in tracing the names of Mongol and Tatar; and now the question arises: Who were the people of Mongol clan or Tatan confederacy? Were they Turks, Tungus, Chinese, or a race apart?

Since the name Mongol or even the name Tatar does not go far back into antiquity, it is necessary to try to trace their origin in the history of the Turks and Tungus. Geographically, however, the area from which the people called Mongol or Tatar originated, corresponds to the Tungus dominions. We know that long before the Christian era (Bichurin, p. 174, 1828) in the district of the Amur there was a powerful state called Sushen, and south of it another called Ilu. Both these peoples were of Tungus race. About the beginning of the Christian era, Ilu subdued Sushen and adopted the name Ugi. This state was composed in the fifth century of seven large clans. In the seventh century they adopted the name Mokho and were then composed of sixteen clans. At the beginning of the ninth century one of the sixteen clans of Mokho moved towards the south-west and adopted the name Tatan. And then we hear that in the tenth century Tatan, which then already formed a confederacy, sent the tribute to China. In the eleventh century they were composed of nine clans of neighbouring people, also of Tungus race. Their organisation was based on the Council of the Elders and on the meeting of clansmen, an organisation slightly different in its representativeness from what we are accustomed to call Mongol autocracy. The power of the head of the confederacy was absolute only in time of war, which is perhaps the explanation of their military success, following, as we all know, unity of command. When in the twelfth century, a Tungus clan, Niudji, attacked one of the Tatan clans, the Mongol, the whole Tatan confederacy stood for the Mongol and the Niudji were conquered and subdued. There is no proof to show that the Mongol clan was of any other race than the whole confederacy. Even their language, at least at the present stage is more akin to some Tungus dialects than to any other language. The only difference between the Mongol clan and the other Tungus was in their environment; they were steppe nomads, while some of the Tungus of that time were agriculturists. Then comes the moment of Mongol history which is well known to Europe. At the end of the twelfth century the head of the Mongol clan, Temudjin, whose nickname was Küsh, became stronger than the other Tungus clans of the Tatan confederacy and in 1206, at a tribal assembly at the source of the River Onon, he compelled the other chiefs by some clever diplomacy, to proclaim. him Khan Jinghis. In that way, the ball originated in this Tungus milieu and rolled towards the west. The Jinghis Khan conquests were more remarkable in Asia than in Europe, and to such belong the conquest of the Turkish states of Central Asia, some of which were devoted Christian Nestorians, while it must be remembered that Jinghis Khan was still a Pagan Shamanist. But while advancing west, both Jinghis Khan himself and his army were becoming more and more influenced by the Turkish language and culture, superior to that of the Tungus. 
The son of Jinghis Khan was educated by a Turkish teacher, a gentleman called Tatatungo, who practically made him a Turk, and all the descendants of Jinghis Khan differed but little from the purely Turkish sovereigns even though they persisted in being called a Mongol or Tatan dynasty. The final amalgamation of the Mongol Tungus element with the Turkish people was accomplished after the Mongol Khans adopted Mahommedanism which in that part of the world is so closely related to Turkish language and culture. It must be remembered that the Tungus were never affected by Mahommedanism, and are either Pagan Shamanists or Lamaists, occasionally also members of the Russian Orthodox Church. . The same can be said about the Mongols of to-day. Viewing the history of North-Central Asia in this light, one cannot understano how it is that this historical dynastic name Mongol has made the ethnologists invent the whole race of "Mongols" to suit the name. It is quite natural that the prestige of the Jinghis Khan conquest could make some prominent historians call their history of North-Central Asia the history of the Mongols, in the same way that the history of Russia might be called the history of the Romanoffs, though the Romanoff was much longer than the Mongol dynasty. Yet one could scarcely approve in ethnology a term "Romanoff race" such as the term Mongol race is used by ethnologists. We can speak at the present time about a Mongol nation since the inhabitants of Mongolia differentiated themselves in their traditions and languages from their neighbours. This nationalist movement among the Mongols has probably been fostered by political reasons, namely, the Russo-Chinese rivalry and the separatist propaganda which Russia carried out in Mongolia against China, and China against Russia. In a way the influence of the Mongol-Buriat educated in Russian schools and universities, and imitating the Russian intelligentsia, has also perhaps helped the recent national awakening. Be this as it may, the town of Urga is now. the centre of the Mongolian nation, not race, a nation more united than are the Tungus or Turkic races of Central Asia, who gave birth to the Mongols. Meanwhile the term Tartar is at the present moment entirely dissociated with the Mongols. Curiously enough, while the name Turk seem to have migrated to the Osmanli, who have less Turkic blood than have any of the Central Asiatic Turks, the most pure Turks, those of Western Siberia, the Altai Mountains and the Volga, are called Tatars. Such are the misleading results of the practice of giving to names which are important in history the same importance in ethnology.

M. A. CZAPLICKA.

Western Papua: Ethnography.

Lyons.

Harina, or Punishment by Substitute-a Custom amongst the Kiwai and Kindred Peoples of Western Papua. By A. P. Lyoris.

According to the tribal laws of those Papuans of.Western New Guinea who are popularly known by the name of Kiwai, and who include the natives living in all coastal villages between the Fly river and Mawatta, as well as those living on the islands and banks of the estuary of that river, death was regarded, at least in theory, as a justifiable punishment to be inflicted for such offences as murder committed either by violence or through a sorcerer, infidelity of wife, stealing another man's property, and a few other transgressions. In practice, however, it depended upon the ability of an aggrieved party to punish, either personally or with the aid of his relatives and friends, whether the law took its course. Crenerally speaking, the law was fairly well upheld.

The injured man, if alive, would rightly constitute himself sole judge of the offender's guilt, and, except when it was forbidden (sabi) by tribal law, or because of his inability to do so personally, he would inflict punishment alone or assisted by his relatives who lived in the same village; but if dead, his eldest son, should 